\title{
Estudo comparativo da proteína do feno de maniçoba em relação à proteína do feno de alfafa na ração de coelhos
}

\author{
[Comparative study of maniçoba hay crude protein in relation to alfafa hay crude \\ protein in the diet of rabbits]
}

\author{
M.S. Brito ${ }^{1}$, J.H.V. Silva, ${ }^{2,4}$, F.G.P. Costa ${ }^{2}$, P.E.N. Givisiez ${ }^{2}$, L.A.F. Pascoal ${ }^{2}$, E.R.A. Oliveira ${ }^{1}$, \\ R.B. Lima ${ }^{1}$, T.R.G. Silva ${ }^{1}$, J.G. Santos ${ }^{3}$, P.H. Watanabe ${ }^{2}$ \\ ${ }^{1}$ Aluno de pós-graduação - Universidade Federal da Paraíba - Areia, PB \\ ${ }^{2}$ Universidade Federal da Paraíba - Areia, PB \\ ${ }^{3}$ Laboratorista - UFPB - Bananeiras, PB) \\ ${ }^{4}$ Bolsista de Produtividade do $\mathrm{CNPq}$
}

\begin{abstract}
RESUMO
O presente experimento foi conduzido com o objetivo de avaliar a substituição parcial da proteína bruta (PB) do feno da alfafa (FA) pela PB do feno de maniçoba (FM) na alimentação de coelhos em crescimento, bem como o valor nutricional da proteína bruta do feno de maniçoba. Foram estudados os parâmetros de desempenho, digestibilidade, rendimento de carcaça e dos cortes nobres submetidos às dietas experimentais. Os tratamentos consistiram em quatro níveis de substituição $(0,25,50$ e $75 \%)$ da proteína do feno de alfafa pelo feno de maniçoba. A substituição crescente dos níveis de feno maniçoba resultou em um aumento linear no consumo de ração e no ganho de peso de forma quadrática aos 83 dias, mostrando que esse ingrediente pode ser utilizado como substituto ao feno de alfafa na dieta de coelhos. A proteína do feno da alfafa pode ser substituída parcialmente pela proteína do feno de maniçoba.
\end{abstract}

Palavras-chave: cunicultura, digestibilidade, Manihot pseudoglaziovii, valor nutricional

\begin{abstract}
The experiment was conducted to evaluate the nutritional value and the partial substitution of crude protein $(C P)$ of alfalfa hay (FA) with $C P$ hay maniçoba (FM) in diets for growing rabbits. The performance, digestibility, carcass yield and prime cuts parameters submitted to experimental diets were studied. Treatments consisted of four levels (0,25, 50 and 75\%) of protein alfalfa hay and maniçoba hay. The increasing substitution levels of maniçoba hay resulted in a linear increase in feed intake and weight gain quadratically at 83 days, showing that this ingredient can be used as a substitute for alfalfa hay in the diet of rabbits. The protein of alfalfa hay can be partially replaced by the maniçoba protein hay.
\end{abstract}

Keywords: digestibility, Manihot pseudoglaziovii, nutritional value, rabbits

\section{INTRODUÇÃO}

O custo da alimentação é o aspecto mais relevante na criação comercial de coelhos, de modo que as fontes proteicas assumem papel importante, tanto sob o ponto de vista nutricional quanto da economia da produção. A principal fonte de fibra utilizada na ração de coelhos é a alfafa (Medicago sativa). No entanto, esse volumoso tem impacto significativo no custo da ração. Neste sentido, a elaboração de dietas compostas de forrageiras nativas como a maniçoba compõe a proposta de regionalização das fórmulas das rações por meio da substituição de ingredientes mais caros e importados de outras regiões por forrageiras locais, visando, sobretudo, à expansão da produção agroalimentar. Assim, a viabilização da criação comercial de coelhos em regiões com pouca disponibilidade de forragem pode representar, na pecuária familiar, importante atividade econômica e social.

Recebido em 3 de março de 2011

Aceito em 6 de novembro de 2012

E-mail: marianybrito@yahoo.com.br 
No Nordeste brasileiro, a flora semiárida não apresenta plantas de grande destaque para a produção de grãos, mas é rica em espécies forrageiras resistentes à seca que garantem a produção de animais herbívoros durante oito a 10 meses do ano (Silva et al., 2006). Em muitos casos, o grande inconveniente dessas forrageiras é a presença de fatores antinutricionais, como o tanino (Costa et al., 2007), e, em geral, os menores valores energéticos dos alimentos. É comum nessas regiões utilizar-se a maniçoba (Manihot pseudoglaziovii Pax e Hoffman) na alimentação animal na forma de feno, devido à presença do ácido cianídrico no material fresco. Além disso, o feno da maniçoba apresenta teor de taninos semelhantes aos de alguns genótipos do sorgo alto tanino (Magalhães e Durães, 2003; Cruz et al., 2007; França et al., 2010) . Mesmo assim, pesquisadores e nutricionistas têm investigado a viabilidade nutricional do feno da maniçoba para ruminantes e não ruminantes (Costa et al., 2007; Silva et al., 2007; Mendonça Júnior et al., 2008;). Portanto, é razoável considerar que os coelhos provavelmente utilizem mais eficientemente o feno da maniçoba comparados a outros animais não ruminantes com resultados economicamente favoráveis. Os coelhos são animais que têm comportamento cecotrofágico; proporcionalmente, maiores quantidades de feno de maniçoba podem ser incluídas na dieta. Resta saber os níveis críticos de inclusão dietética na alimentação desses animais. Desta forma, objetivou-se avaliar os efeitos da substituição parcial da proteína do feno de alfafa pela proteína do feno de maniçoba na alimentação de coelhos na fase de crescimento.

\section{MATERIAL E MÉTODOS}

O experimento foi realizado no Setor de Cunicultura do Centro de Ciências Humanas, Sociais e Agrárias no município de Bananeiras, Universidade Federal da Paraíba. As médias de temperatura e umidade do ar durante o ensaio de metabolismo foram $23,4 \pm 2^{\circ} \mathrm{C}, 88 \pm 8 \%$ e $25,3 \pm 5^{\circ} \mathrm{C}, 82 \pm 30 \%$ para o experimento de desempenho.

O ensaio de metabolismo foi realizado com 14 coelhos da raça Nova Zelândia Vermelho (machos e fêmeas) aos 50 dias de idade. $\mathrm{O}$ delineamento experimental utilizado foi inteiramente ao acaso, com dois tratamentos e sete repetições de um animal. Os animais foram alojados em gaiolas de arame galvanizado, equipadas com comedouro, bebedouro e bandejas para a coleta total de fezes.

A ração-referência (Tab. 1) foi formulada de acordo com as recomendações do NRC National (1977) para coelhos em crescimento. A raçãoteste foi composta por $70 \%$ da ração- referência e $30 \%$ de feno de maniçoba. Em seguida, as rações foram peletizadas a seco e fornecidas à vontade.

O período experimental durou 11 dias, sendo os sete primeiros para adaptação dos animais às gaiolas e às rações experimentais e os quatro últimos para as coletas de fezes. A determinação da digestibilidade da dieta seguiu a metodologia descrita por EGRAN (1995).

Os animais, as rações e as sobras foram pesadas no início e no final do período de coletas. As fezes foram pesadas, após retirada dos pelos, em seguida congeladas. As coletas foram realizadas pela manhã. Ao final do período de coleta, o material fecal coletado de cada animal foi descongelado e homogeneizado para retirada de uma amostra composta de $150 \mathrm{~g}$. As amostras foram pré-secas em estufa a $55^{\circ} \mathrm{C}$, por 72 horas, moídas em moinho do tipo Willye, com peneira de 2,0mm. Os pelos remanescentes foram removidos. As amostras de ração foram moídas, seguindo os mesmos procedimentos adotados para as fezes.

As amostras das rações e fezes foram analisadas para matéria seca (MS), matéria mineral (MM), proteína bruta $(\mathrm{PB})$, extrato etéreo $(\mathrm{EE})$, fibra em detergente neutro (FDN) e fibra em detergente ácido (FDA), de acordo com as metodologias descritas em Silva e Queiroz (2002). A energia bruta (EB) das rações e das excretas foi medida em bomba calorimétrica PARR.

Os coeficientes de digestibilidade da MS, PB, EE, EB do feno de maniçoba foram calculados tendo por base as equações propostas por Matterson et al. (1965) com 30\% do ingredienteteste.

No experimento de desempenho, foram utilizados 56 coelhos (28 machos e 28 fêmeas) da raça Nova Zelândia Vermelho, com média de peso inicial de $0,749 \pm 0,07 \mathrm{~kg}$. Aos 50 dias de idade, os animais foram alojados em gaiolas 
metálicas dotadas de comedouro e bebedouro de cerâmica. As gaiolas foram instaladas em galpão de alvenaria com piso de alvenaria e cobertura de telha francesa, com pé-direito de 3,0m. O período experimental teve duração de 33 dias.

Os animais foram distribuídos em delineamento inteiramente ao acaso, com quatro tratamentos e sete repetições de dois animais por unidade experimental (um macho e uma fêmea). Os tratamentos consistiram de uma raçãotestemunha e três níveis de substituição $(25,50$ e $75 \%$ ) da proteína do feno de alfafa pela proteína do feno de maniçoba (Tab. 1). As rações foram formuladas de acordo com as recomendações nutricionais do NRC National (1977) para coelhos em crescimento. Após a formulação, as rações foram peletizadas.

Tabela 1. Composição centesimal e química das rações experimentais na matéria natural

\begin{tabular}{|c|c|c|c|c|}
\hline \multirow[b]{2}{*}{ Ingredientes } & \multicolumn{4}{|c|}{ Nível de PB do feno de maniçoba (\%) } \\
\hline & 0 & 25 & 50 & 75 \\
\hline Milho grão & 56,42 & 52,16 & 47,92 & 43,67 \\
\hline Farelo de soja & 14,70 & 15,01 & 15,32 & 15,63 \\
\hline Farelo de trigo & 3,23 & 5,48 & 5,16 & 6,13 \\
\hline Feno de alfafa $(17,38 \%$ PB $)$ & 21,08 & 15,81 & 10,53 & 5,29 \\
\hline Feno de maniçoba $(14,38 \% \mathrm{~PB})$ & --- & 6,18 & 12,29 & 18,47 \\
\hline Bagaço de cana & --- & 0,79 & 4,22 & 6,24 \\
\hline Óleo de soja & 2,00 & 2,00 & 2,00 & 2,00 \\
\hline Fosfato bicálcico & 1,34 & 1,33 & 1,33 & 1,33 \\
\hline Sal comum & 0,43 & 0,43 & 0,43 & 0,43 \\
\hline Premix vitamínico-mineral $^{1}$ & 0,50 & 0,50 & 0,50 & 0,50 \\
\hline Metionina & 0,19 & 0,20 & 0,20 & 0,21 \\
\hline Lisina & 0,10 & 0,10 & 0,09 & 0,09 \\
\hline Hidroxitolueno butilado & 0,01 & 0,01 & 0,01 & 0,01 \\
\hline Total & 100,00 & 100,00 & 100,00 & 100,00 \\
\hline \multicolumn{5}{|c|}{ Composição nutricional } \\
\hline Matéria seca $(\%)^{1}$ & 88,57 & 88,26 & 88,61 & 88,79 \\
\hline Matéria orgânica $(\%)^{1}$ & 84,28 & 84,28 & 83,95 & 83,71 \\
\hline Proteína bruta $(\%)^{1}$ & 15,31 & 15,44 & 15,20 & 15,15 \\
\hline Extrato etéreo $(\%)^{1}$ & 4,57 & 3,77 & 4,07 & 4,27 \\
\hline Fibra em detergente neutro $(\%)^{1}$ & 20,39 & 21,56 & 22,72 & 23,88 \\
\hline Fibra em detergente ácido $(\%)^{1}$ & 11,22 & 12,02 & 12,83 & 13,65 \\
\hline Matéria mineral $(\%)^{1}$ & 4,52 & 3,90 & 4,88 & 5,26 \\
\hline Energia digestível (kcal/kg) & 2.500 & 2.500 & 2.500 & 2.500 \\
\hline
\end{tabular}

${ }^{1}$ Composição por kg do produto: vit. A, 660.000UI; vit. D3, 60.00UI; vit. E, 4.000mg; vit. $\mathrm{K}_{3}$, 400mg; vit. $\mathrm{B}_{2}$, 400mg; vit. $\mathrm{B}_{12}, 2.400 \mu \mathrm{g}$; ac. pantotênico, 2.080mg; ac. nicotínico, 3.600mg; B.H.T., 6.000mg; ferro, 16.200mg; selênio, 60mg; olaquindox, $8.000 \mathrm{mg}$; lisina, $50.000 \mathrm{mg}$; cobre, $1.400 \mathrm{mg}$; zinco, $20.200 \mathrm{mg}$; manganês, $2.000 \mathrm{mg}$. iodo, $48 \mathrm{mg}$.

${ }^{1}$ Valores analisados.

Os animais e as sobras de ração foram pesados no início e no final do experimento para determinação do ganho de peso, do consumo de ração e da conversão alimentar. Aos 83 dias de idade, os animais foram submetidos a um jejum alimentar de 12 horas. Em seguida, os animais foram insensibilizados, sacrificados e eviscerados. As carcaças foram pesadas sem patas e cabeça para obtenção dos pesos da carcaça. Foram realizadas pesagens da pele, do fígado, dos rins, da gordura e das patas. O comprimento do intestino delgado e do intestino grosso foi mensurado.
O rendimento da carcaça foi mensurado em relação ao peso vivo enquanto que o rendimento das paletas, do Longissimus lumborum e do Biceps femoris foram mensurados em relação ao peso da carcaça. Também foram observadas as médias de $\mathrm{pH}$ da carcaça, do Biceps femoris e da carcaça 24 horas após o abate.

Os cortes comerciais foram realizados de acordo com Blasco e Ouhayoun (1993). As coxas foram seccionadas na sétima vértebra, e posteriormente foram obtidos o longissimus lumborum, o Biceps femoris e as paletas. 
A biometria do intestino delgado foi analisada pela retirada de fragmentos de $1 \mathrm{~cm}$ de comprimento das porções médias do duodeno, jejuno e íleo de quatro animais por tratamento. As amostras foram lavadas, imersas em solução de Bouin por 48 horas e, em seguida, conservadas em álcool. Após serem fixadas em parafina e coradas, as amostras foram comparadas. Avaliaram-se a altura das vilosidades, a profundidade de criptas intestinais e a relação altura das vilosidades: profundidade de criptas. Para a avaliação morfométrica, utilizou-se microscópio binocular equipado com câmara para a seleção de imagens com objetiva de 10X. As imagens foram analisadas utilizandose o programa IMAGE J. ${ }^{\circledR} 4.1$.

Os dados foram submetidos à análise de variância, considerando-se nível de significância até 5\%. Quando houve significância da variável, foi aplicada a análise de regressão considerandose o ajuste linear e quadrático dos dados conforme o melhor ajuste do modelo obtido para cada variável.

\section{RESULTADOS E DISCUSSÃO}

Os valores centesimais de feno de maniçoba estão descritos na Tab. 2.

Tab. 2. Valores médios para matéria seca, umidade, proteína bruta, fibra em detergente neutro, fibra em detergente ácido, hemicelulose, extrato etéreo e matéria mineral do feno de maniçoba na matéria natural

\begin{tabular}{lc}
\hline Nutriente & $\%$ \\
\hline Matéria seca & 86,98 \\
Umidade & 80,01 \\
Proteína bruta & 14,89 \\
Fibra em detergente neutro & 38,22 \\
Fibra em detergente ácido & 33,50 \\
Hemicelulose & 6,97 \\
Extrato etéreo & 4,70 \\
Cinzas & 4,97 \\
\hline
\end{tabular}

As análises bromatológicas indicaram que o feno de maniçoba pode ser um alimento alternativo em potencial, que venha a ser utilizado em dietas de coelhos em manutenção ou crescimento. Destacam-se os teores de proteína bruta, fibra e NDT (National..., 1977) que se assemelham à silagem do sorgo (Furlan et al., 2006).
Os valores bromatológicos do feno da maniçoba correspondem aos encontrados por outros autores (Castro et al., 2007; Mendonça Júnior et al., 2008), com variações explicadas pela variabilidade genética da maniçoba, pela época do ano, pela fertilidade do solo, pelo estágio vegetativo e pela proporção de folhas:caules do material fenado.

$\mathrm{O}$ alto teor da FDA, composta principalmente por celulose e, em menor parte, pela lignina, provavelmente afetou negativamente os coeficientes de digestibilidade do feno da maniçoba. O estágio vegetativo da maniçoba tem implicações na digestibilidade devido ao grau de lignificação dos tecidos da planta bem como à baixa relação caule: folha presente na forrageira no momento do corte. Resultado semelhante foi descrito por França et al. (2010). Para ilustrar esses efeitos, os referidos autores disponibilizaram imagens histológicas das amostras degradadas de folhas e caules do feno da maniçoba com gradientes de lignificação celular. As imagens sinalizam a redução da digestibilidade dos nutrientes com o desenvolvimento da planta.

A coleta extrativista da maniçoba resultou em que a maioria das plantas utilizadas neste experimento havia frutificado. Logo, a maturidade da planta provavelmente reduziu os coeficientes de digestibilidade da MS, PB, EE, EB, conforme demonstrado na Tab. 3.

A digestibilidade dos nutrientes do feno da maniçoba foi moderadamente baixa, mas não afetou o ganho de peso e o consumo de ração, demonstrado na Tab. 4.

A eficiência de utilização do feno da maniçoba pelos coelhos reduziu com o aumento da inclusão, mas não afetou da mesma forma o ganho de peso, que aumentou até o nível de $58 \%$ de substituição. Mais da metade da PB do feno da alfafa foi substituído pela PB do feno da maniçoba sem comprometer o peso dos animais aos 83 dias de vida.

O feno de alfafa possui em sua composição em torno de 1,64\% de tanino (Cruz et al., 2007) e $0,82 \%$ de feno da alfafa (Vieira et al., 2001). 
Estudo comparativo da proteína...

Tabela 3. Coeficientes de digestibilidade, nutrientes digestíveis e valores energéticos do feno de maniçoba na matéria natural

\begin{tabular}{lcc} 
Nutriente & $\begin{array}{c}\text { Coeficiente digestibilidade } \\
(\%)\end{array}$ & $\begin{array}{c}\text { Nutrientes digestíveis (\%) e Energia } \\
\text { digestível }(\mathrm{kcal} / \mathrm{kg})\end{array}$ \\
\hline Matéria seca & 67,40 & 58,63 \\
Proteína bruta & 35,05 & 5,22 \\
Extrato etéreo & 11,87 & 0,59 \\
Energia bruta $(\mathrm{kcal} / \mathrm{kg})$ & 29,71 & 709 \\
\hline
\end{tabular}

Tabela 4. Consumo diário de ração (CDR), ganho de peso (GP) e conversão alimentar (CA) em função dos níveis de substituição da proteína bruta (PB) do feno de alfafa pela PB do feno de maniçoba

\begin{tabular}{lccccc}
\hline \multirow{2}{*}{ Variável } & \multicolumn{3}{c}{ Nível da PB do feno de maniçoba $(\%)$} & \\
\cline { 2 - 5 } & 0 & 25 & 50 & 75 & CV $(\%)$ \\
\hline CR (g/dia) ${ }^{1}$ & 66,66 & 65,15 & 84,85 & 83,33 & 9,00 \\
GP (g/dia) & 27,21 & 30,15 & 32,12 & 30,90 & 8,47 \\
CA (kg/kg) & 2,48 & 2,17 & 2,64 & 2,71 & 10,37 \\
\hline
\end{tabular}

${ }^{1}$ Efeito linear $(\mathrm{P}<0,05)$.

${ }^{2}$ Efeito quadrático $(\mathrm{P}<0,05)$.

Pesquisas realizadas com maniçoba na alimentação animal sugerem que, em geral, os taninos condensados presentes no vegetal são responsáveis pela redução no consumo de alimento pelo animal e pela diminuição nos valores de digestibilidade da proteína bruta e do extrato etéreo (Getacgew et al., 2000; Araújo e Cavalcanti, 2002; Cruz et al., 2007). No entanto, observou-se que o consumo foi maior para os animais que receberam maiores quantidades de feno de maniçoba. Esses grupos também apresentaram maior ganho de peso comparados ao tratamento sem feno de maniçoba e ao tratamento com $25 \%$ de substituição da PB do feno da alfafa pela PB do feno de maniçoba. Assim, a diminuição da eficiência alimentar que resultou em piores valores de conversão alimentar pode ter resultado da maior quantidade de FDA das rações com maiores quantidades de feno de maniçoba e não apenas pelo teor de taninos. Como mencionado anteriormente, o alto teor da FDA que é composta pela celulose e lignina, influenciada pelo avançado estágio vegetativo das plantas de maniçoba utilizadas na produção do feno, alterou a digestibilidade devido ao elevado grau de lignificação dos tecidos da planta; fato semelhante ao observado no presente trabalho também foi constatado por França et al. (2010). Tais resultados explicariam a diminuição da eficiência alimentar mesmo quando os teores de proteína bruta e energia digestível das dietas experimentais foram mantidos em níveis semelhantes.

O consumo dos grupos que receberam maiores quantidades de feno de maniçoba aumentou, os animais ganharam mais peso, sem alterar a quantidade de gordura na carcaça. Desta forma, as carcaças dos animais foram mais pesadas e com maiores teores absolutos de carne magra (Tab. 5). Os rendimentos das paletas, do Longissimus lumborum e do Biceps femoris, mensurados em relação ao peso da carcaça, não apresentaram diferença entre os tratamentos $(\mathrm{P}>0,05)$.

Apesar do aumento no comprimento do intestino delgado para os grupos de coelhos alimentados com os níveis 25 e $50 \%$ de substituição da $\mathrm{PB}$ do FA pela PB do FM em relação ao grupocontrole, os pesos relativos dos rins e fígado não foram influenciados pelo aumento do nível de substituição e pela maior proporção do feno de maniçoba na dieta como fonte de fibra. No entanto, a morfologia da mucosa intestinal foi afetada pelos tratamentos.

Observou-se que, com a inclusão do feno da maniçoba, houve encurtamento da vilosidade do duodeno, enquanto a altura da vilosidade no jejuno aumentou linearmente (Tab. 6). 
Tabela 5. Médias dos pesos vivo (PV), de carcaça (PC), pele (PEL), fígado (FIG), rins (RIN), gordura (GOR) e patas (PTA), comprimentos do intestino delgado (CID) e do intestino grosso (CIG) em função dos níveis de substituição da PB do feno de alfafa pela PB do feno de maniçoba

\begin{tabular}{lccccc}
\multirow{2}{*}{ Variável } & \multicolumn{3}{c}{ Nível de PB do feno de maniçoba (\%) } & CV $(\%)$ \\
\cline { 2 - 5 } & 0 & 25 & 50 & 75 & \\
\hline PV (kg) & 1,640 & 1,790 & 1,920 & 1,783 & 4,80 \\
PC (kg) ${ }^{1}$ & 0,816 & 0,855 & 0,931 & 0,878 & 5,88 \\
PEL (kg) & 0,149 & 0,207 & 0,210 & 0,196 & 8,93 \\
FIG (kg) & 0,067 & 0,073 & 0,065 & 0,058 & 18,45 \\
RIN (kg) & 0,010 & 0,011 & 0,011 & 0,010 & 21,24 \\
GOR (kg) & 0,032 & 0,051 & 0,051 & 0,040 & 28,48 \\
PTA (kg) & 0,057 & 0,058 & 0,060 & 0,058 & 7,10 \\
CID (m) & 2,087 & 2,234 & 2,170 & 2,063 & 12,66 \\
CIG (m) & 1,444 & 1,380 & 1,469 & 1,328 & 12,17 \\
\hline
\end{tabular}

${ }^{1}$ Efeito quadrático $(\mathrm{P}<0,05)$.

Tabela 6. Análise morfométrica do epitélio intestinal em função dos níveis de substituição da proteína bruta (PB) do feno de alfafa pela PB do feno de maniçoba

\begin{tabular}{|c|c|c|c|c|c|}
\hline \multirow[t]{2}{*}{ Morfometria $(\mu \mathrm{m})$} & \multicolumn{4}{|c|}{ Nível de feno de feno de maniçoba (\%) } & \multirow[t]{2}{*}{$\mathrm{CV}(\%)$} \\
\hline & 0 & 25 & 50 & 75 & \\
\hline \multicolumn{6}{|c|}{ Altura vilosidade (AV) } \\
\hline Duodeno $^{\mathrm{a}}$ & 1080,12 & 1079,00 & 1010,71 & 882,64 & 2,97 \\
\hline Jejuno $^{\mathrm{b}}$ & 884,13 & 958,55 & 1044,48 & 1097,06 & 2,69 \\
\hline Íleo $^{\mathrm{a}}$ & 519,24 & 956,97 & 1010,71 & 670,97 & 27,85 \\
\hline \multicolumn{6}{|c|}{ Profundidade cripta (PC) } \\
\hline Duodeno $^{\mathrm{a}}$ & 63,49 & 84,15 & 76,12 & 83,36 & 10,67 \\
\hline Jejuno $^{\mathrm{a}}$ & 65,16 & 84,81 & 82,26 & 83,37 & 8,66 \\
\hline Íleo $^{a}$ & 58,93 & 78,52 & 76,12 & 73,78 & 11,41 \\
\hline \multicolumn{6}{|l|}{ Relação AV:PC } \\
\hline Duodeno $^{\mathrm{a}}$ & 17,01 & 12,82 & 13,28 & 10,59 & 11,91 \\
\hline Jejuno $^{a}$ & 13,57 & 11,30 & 12,70 & 13,16 & 9,11 \\
\hline Íleo & 8,81 & 12,19 & 13,28 & 9,09 & 20,68 \\
\hline
\end{tabular}

${ }^{\mathrm{a}}$ Efeito quadrático $(\mathrm{P}<0,05)$.

${ }^{\mathrm{b}}$ Efeito linear $(\mathrm{P}<0,05)$.

Para justificar a importância do seu trabalho, Arruda et al. (2008) comentam os resultados alcançados por diversos autores de que a fibra da dieta de coelhos promove alterações morfológicas na mucosa intestinal, as quais modificam a altura das vilosidades e a profundidade das criptas. Apesar da variabilidade dos resultados, os dados histológicos da mucosa intestinal de coelhos obtidos por Arruda et al. (2008) resultaram em comportamento semelhante aos observados neste experimento com o aumento da FDA da dieta. Adicionalmente, a maior altura dos vilos tanto do jejuno quanto do íleo para o nível $50 \%$ de substituição da PB do FA pela PB do FM ajuda a explicar por que os animais desse grupo apresentaram os melhores resultados de ganho de peso, em virtude de maiores alturas das vilosidades nessas regiões do intestino delgado se correlacionarem com o aumento na absorção de nutrientes. Contudo, a relação vilo: cripta variou pouco entre os tratamentos.

A substituição da proteína do feno da alfafa pela proteína do feno da maniçoba não alterou os parâmetros de $\mathrm{pH}$ da carcaça e do Biceps femoris.

A composição química e o teor de taninos do feno da maniçoba são semelhantes aos encontrados em alguns genótipos de sorgo alto tanino (Magalhães e Durães, 2003; Cruz et al., 
2007; França et al., 2010), sugerindo que a inclusão do feno de maniçoba na ração pode causar efeitos semelhantes àqueles do sorgo de alto tanino. Genótipos de sorgo de alto tanino têm sido empregados na composição de dietas para não ruminantes sem comprometer os parâmetros de desempenho e de rendimento de carcaça (Garcia et al., 2005), a exemplo do que ocorre com o sorgo, em que técnicas de baixo custo como a ensilagem podem diminuir os efeitos atribuídos aos taninos e melhorar a disponibilidade dos nutrientes para os animais não ruminantes (Borges, 1999; Furlan et al., 2006). Outro aspecto a ser considerado é que, em ensaios de digestibilidade utilizando a metodologia tradicional de coleta total de fezes realizados com coelhos, os valores reais dos ingredientes alternativos são subestimados, uma vez que os cecotrofos não são considerados. Mas é razoável considerar que, após a cecotrofagia, a contribuição nutricional dos volumosos, como o feno de maniçoba, passa a ser ainda maior.

A criação de coelhos pode representar uma alternativa para pequenas propriedades. Pesquisas que viabilizem alimentos não convencionais, de baixo custo e fácil manipulação como o feno de maniçoba, podem contribuir para a expansão da produção agroalimentar em regiões onde a variedade de alimentos disponíveis para os animais é bastante limitada por apresentarem limitações alto teor de fibras, baixo de proteína e a baixa relação folhas: caule da maiorias das espécies. Assim, a sustentabilidade dos sistemas de produção animal nessas regiões depende da identificação e da caracterização nutricional dos recursos forrageiros nativos disponíveis, como a maniçoba, e do incentivo à inclusão dessas espécies na formulação das dietas animais. Portanto, a presente proposta visou difundir, com base em critérios biológicos, o uso do feno de maniçoba como volumoso fibroso em substituição ao feno de alfafa na alimentação de coelhos em crescimento.

\section{CONCLUSÕES}

A proteína do feno de maniçoba pode substituir a proteína do feno de alfafa em até $58 \%$ na ração de coelhos em crescimento.

\section{REFERÊNCIAS}

ARAUJO, G.G.L.; CAVALCANTI, J. Potencial de utilização da maniçoba. In: SIMPÓSIO PARAIBANO DE ZOOTECNIA, 3., 2002. Areia, PB. Anais... Areia, PB [UNITREINO] 2002. p.01-15.

ARRUDA, A.M.V.; FERNANDES, R.T.V.; SILVA, J.M.; LOPES, D.C. Avaliação MorfoHistologica da mucosa intestinal de coelhos alimentados com diferentes níveis e fontes de fibra. Caatinga, v.21, p.1-11, 2008.

BORGES, A.L.C.C.; GONÇALVES, L.C.; NOGUEIRA, F.S. et al. Silagem de sorgo de porte baixo com diferentes teores de tanino e de umidade no colmo. II - Alterações nos carboidratos durante a fermentação. Arq. Bras. Med. Vet. Zootec., v.51, p.491-497, 1999.

BLASCO, A.; OUHAYOUN, J. Harmonization of criteria and terminology in rabbit meat research. Revised proposal. W. Rabbit Sci., v.4, p.93-99, 1993.

CASTRO, J.M.C.A.; SILVA, D.S.; MEDEIROS, A.N. et al. Desempenho de cordeiros Santa Inês alimentados com dietas completas contendo feno de maniçoba. Rev. Bras. Zootec., v.36, p.674680, 2007.

COSTA, F.G.P.; OLIVEIRA, C.F.S.; BARROS, L.R. et al. Valores energéticos e composição bromatológica dos fenos de jureminha, feijão bravo e maniçoba para aves. Rev. Bras. Zootec., v.36, p.813-817, 2007.

CRUZ, S.E.S.B.S.; BEELEN, P.M.G.; SILVA, D.S. et al. Caracterização dos taninos condensados das espécies maniçoba (Manihot pseudoglazovii), flor-de-seda (Calotropis procera), feijão-bravo (Capparis flexuosa, L) e jureminha (Desmanthus virgatus). Arq. Bras. Med. Vet. Zootec., v.59, p.1038-1044, 2007.

EGRAN- European reference method for in vivo determination of diet digestibility in rabbits. $W$. Rabbit Sci., v.3, p.41-43, 1995.

FRANÇA, A.A.; GUIM, A.; BATISTA, A.M.V. et al. Anatomia e cinética de degradação do feno de manihot glaziovii. Acta Sc. Anim. Sci., v.32, p.131-138, 2010. 
FURLAN, A.C.; SCAPINELLO, C.; MOREIRA, I.; MARTINS, E.N. Avaliação nutricional da silagem de grãos úmidos de sorgo de baixo ou de alto conteúdo de tanino para coelhos em crescimento. Rev. Bras. Zootec., v.35, p.775-784, 2006.

GARCIA, R.G.; MENDES, A.A.; ANDRADE, C. et al. Avaliação do desempenho e de parâmetros gastrintestinais de frangos de corte alimentados com dietas formuladas com sorgo alto tanino e baixo tanino. Cienc. Agrotec., v.29, p.1248-1257, 2005.

GETACGEW, G.; MAKKAR, H.P.S.; BECKER, K. Effect of polyethylene glycol on in vitro degradability of nitrogen and microbial protein synthesis from tannin-rich browse and herbaceous legumes. Br. J. Nutr., v.84, p.73-83, 2000 .

MAGALHÃES, P.C.; DURÃES F.O.M. Tanino no grão de sorgo florada. Planaltina: Embrapa Cerrados - Comunicado Técnico 88, 2003. (Comunicado Técnico).

MATTERSON, L.D.; POTTER, L.M.; STUTZ, M.W. et al. The metabolizable energy of feed ingredients for chickens. Agric. Exper. Stat. Res. Report, v.7, p.11-14, 1965.
MENDONÇA JÚNIOR, A.F.; BRAGA, A.P.; CAMPOS, M.C.C. et al. Avaliação da composição química, consumo voluntário e digestibilidade in vivo de dietas com diferentes níveis de feno de maniçoba (Manihot glaziovii Muell. Arg.), fornecidas a ovinos. Rev. Bio. Cienc. Terra, v.8, p.32-41, 2008.

NATIONAL research coucil - NRC. Nutrient requirements of rabbits. 2. ed., 1977. 30p.

SILVA, D.S.; CASTRO, J.M.C.; MEDEIROS, A.N. et al. Feno de maniçoba em dietas para ovinos: consumo de nutrientes, digestibilidade aparente e balanço nitrogenado. Rev. Bras. Zootec., v.36, p.1685-1690, 2007.

SILVA, J.H.V.; COSTA, M.R.; COSTA, S.M.V. et al. Avaliação do biofermentado a base de plantas nativas semi-áridas (BIONAT) na ração de frangos de corte. In: CONGRESSO NORDESTINO DE PRODUÇÃO ANIMAL, 4., 2006. Petrolina. Anais... Petrolina: [Gmosis] 2006. (Resumo).

SILVA, D.J.; QUEIROZ, A.C. Análise de alimentos: métodos químicos e biológicos. 3.ed. Viçosa, MG: Editora UFV, 2002. 165p.

VIEIRA, M.E.Q.; COSTA, C.; SILVEIRA, A.C. Porcentagens de saponinas e taninos em vinte e oito cultivares de alfafa (Medicago sativa L.) em duas épocas de corte - Botucatu - SP. Rev. Bras. Zootec., v.30, p.1432-1438, 2001. 